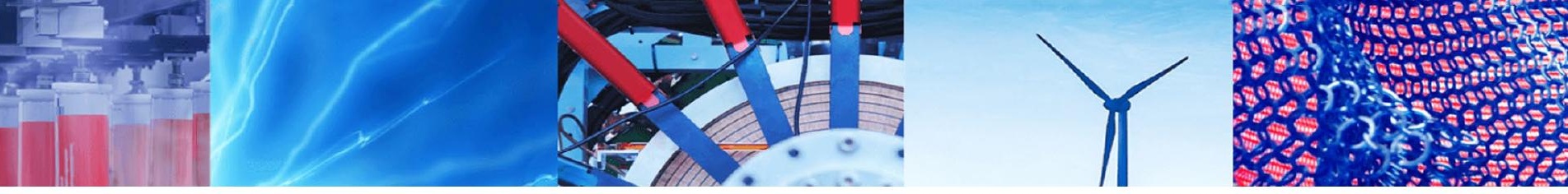

Review Paper

\title{
The research progress on corrosion and protection of silver layer
}

\author{
Huiru Zhang $^{1} \mathbb{D} \cdot$ Xiaolong Xue $^{1}$ \\ (c) Springer Nature Switzerland AG 2019
}

\begin{abstract}
In this paper, the mechanism and reason of silver corrosion and discoloration are discussed. The analysis and characterization of silver corrosion layer and the cleaning method of the discoloration part of silver are described. There are two methods for silver anti-corrosion and anti-tarnish. One is to develop anti-discoloration silver alloy. The other is to treat silver layer surface, which includes: surface plating, surface passivation, surface coating (Resin Coating, RC; Plasmapolymer Coating, PC; Organic Adsorption Complex Membrane, OACM; Supramolecular Self-Assembly, SSA), and surface deposition (Megnetron Sputtering, MS; Plasma Beam Sputtering, PBS; Chemical Vapor Deposition, CVD; Atomic Layer Deposition, ALD). It has great potential for SSA and ALD technologies to be applied in the silver corrosion protection. Furthermore, the technological requirements of silver anti-corrosion are listed and the need for silver anti-corrosion to be comprehensively controlled from all aspects is also proposed.
\end{abstract}

Keywords Silver layer $\cdot$ Corrosion $\cdot$ Protection $\cdot$ Research progress

\section{Introduction}

Noble-metal nanoparticles (AgNPs, AuNPs) have had a substantial impact on diverse fields, including catalysis, sensing, photochemistry, optoelectronics, energy conversion and medicine. Although Ag has very desirable physical properties (long-lasting antibacterial ability and bacteriostasis, electric conduction, heat conduction, safety and reliability of anti-electromagnetic wave radiation) with good relative abundance and low cost, AuNPs have been widely favored owing to their proven stability and ease of use. Unlike Au, Ag is notorious for its susceptibility to oxidation (tarnishing), which has limited the development of important Ag-based nanomaterials. Despite two decades of synthetic efforts, AgNPs that are inert or have long-term stability remain unrealized.

Accordingly, the anti-corrosion and anti-tarnish research of Ag-based material has been highly valued by domestic and foreign counterparts. For a long time, a large number of researchers have been working hard to develop the corrosion protection and anti-tarnishing property of
Ag. There is a hope of preventing or effectively slowing down the Ag discoloration, which has great practical significance for the extensive and durable use of Ag-based functional materials. In particular, it can further meet the needs of high-end products, national defense industry, extreme environment and special fields.

\section{Corrosion and discoloration of $\mathbf{A g}$}

Corrosion and discoloration phenomenon will inevitably occur in the storage and use of Ag products. There are mainly three chemical factors that cause corrosion and discoloration of Ag materials [1-9].

1. Corrosion Media. In the atmosphere, there is oxygen $\left(\mathrm{O}_{2}\right)$, slight or trace hydrogen sulfide $\left(\mathrm{H}_{2} \mathrm{~S}\right)$, elemental sulfur $\left(\mathrm{S}_{8}\right)$, sulfur dioxide $\left(\mathrm{SO}_{2}\right)$, organic sulfide (OCS, $\mathrm{CS}_{2}, \mathrm{CH}_{3} \mathrm{SCH}_{2}$ ), nitride (NOx, $\mathrm{NH}_{3}, \mathrm{HNO}_{3}$ ), mixture of various gases, free radicals and peroxides $\left(\mathrm{H}_{2} \mathrm{O}_{2}, \mathrm{O}_{3}\right)$, chloride $\left(\mathrm{Cl}_{2}, \mathrm{HCl}\right)$, carbide $\left(\mathrm{CO}_{2}\right)$, organics $(\mathrm{HCHO}$,

Huiru Zhang, zhanghuiru@shu.edu.cn | 1 College of Materials Science and Engineering, Shanghai University, Shanghai 200444, China.

SN Applied Sciences (2019) 1:464 | https://doi.org/10.1007/s42452-019-0495-3 
$\left.\mathrm{HCOOH}, \mathrm{CH}_{3} \mathrm{COOH}\right)$, and sulfide solution $\left(\mathrm{Na}_{2} \mathrm{~S}\right.$, $\mathrm{NaHS})$. These corrosive media make $\mathrm{Ag}$ be corroded into sulfides and sulphates $\left(\mathrm{Ag}_{2} \mathrm{~S}, \mathrm{Ag}_{2} \mathrm{SO}_{3}, \mathrm{Ag}_{2} \mathrm{SO}_{4}\right.$ $\mathrm{Ag}_{2} \mathrm{~S}_{2} \mathrm{O}_{3}$ ), oxide and carbonate ( $\mathrm{AgO}, \mathrm{Ag}_{2} \mathrm{O}, \mathrm{a}-\mathrm{Ag}_{2} \mathrm{CO}_{3}$, $\left.\beta-\mathrm{Ag}_{2} \mathrm{CO}_{3}, \gamma-\mathrm{Ag}_{2} \mathrm{CO}_{3}\right)$, chloride ( $\left.\mathrm{AgCl}\right)$, nitrogen compounds $\left(\mathrm{AgNO}_{3}\right)$, organic compounds $\left(\mathrm{AgCO}_{2} \mathrm{CH}_{3}\right.$, $\left.\mathrm{AgCO}_{2} \mathrm{H}, \mathrm{Ag}_{2} \mathrm{C}_{2} \mathrm{O}_{4}\right)$, and corresponding Ag layer discoloration.

2. Environmental Factors, such as temperature, humidity and light. The high temperature, high humidity and strong light, especially ultraviolet light can accelerate Ag ionization and impel Ag corrosion and discoloration.

3. Surface Morphology of Ag. The Ag with lattice defects is more erosive and discoloring than that with lattice integrity.

In addition, the discoloration of $\mathrm{Ag}$ is also influenced by physical factors $[10,11]$. When the specific frequency of the light is irradiated on the surface of the metal nanoparticles, Local Surface Plasmon Resonance (LSPR) effect of metal nanoparticles, namely, LSPR adsorption or LSPR radiation makes the nano structure metal take on a specific color. The morphology of Ag products (particle size, shape and compactness degree) can be changed due to the preparation conditions and heat treatment, so that the LSPR properties of the Ag surface are changed, which leads to the color change of the Ag products.

The corrosion and discoloration of Ag have complexity and multiplicity. Under the influence of multiple factors, Ag is more vulnerable to corrosion. It displays pitting corrosion, darkening and spots, and appears blue, black and so on. This phenomenon not only affects beauty, but still can weaken the good performance of Ag products and result in its loss.

\section{Analysis, characterization and cleaning of Ag corrosion layer}

In order to effectively prevent Ag products from corrosion, clean Ag corrosion layer, and recover from Ag discoloration, it is necessary to analyze and characterize the corrosion layer and the discoloration part of Ag.

To produce Ag corrosion and discoloration layer, on the one hand, the experiments in natural conditions are employed, namely outdoor test method, which can truly reflect the discoloration and performance of $\mathrm{Ag}$ products in a certain environment, but the test time is long and the result reproducibility is low. On the other hand, laboratory simulation accelerated test is adopted, namely laboratory test method, which includes liquid phase test $\left(\mathrm{Na}_{2} \mathrm{~S}\right.$, artificial sweat, salt water, etc., with solution immersion); gas phase test $\left(\mathrm{H}_{2} \mathrm{~S}, \mathrm{SO}_{2}\right.$, and mixed gas); and illumination test. Accelerated corrosion test has good operability, reproducibility, and short test time, so it is the commonly adopted method to produce the discoloration part and corrosion layer of the Ag.

The analysis and characterization of the Ag discoloration part and corrosion layer mainly includes:

1. Naked Eye Observation is to carry out corrosion appearance rating, for which the Ag appearance is rated based on the change degree of luminance and cleanliness, such as color changing, color losing, pitting corrosion, changes about corrosion products, et al.

2. Spectrophotometer Method is the quantitative analysis of Ag products color. It can show the discoloration degree of Ag for a certain period of time, directly reflecting the anti-discoloration performance of Ag.

3. Weighing Method is to measure the mass change $(\Delta \mathrm{m})$ of Ag products when there is the occurrence of Ag corrosion. Test accuracy can reach nano-gram level (ng $=10^{-9} \mathrm{~g}$ ) when using Quartz Crystal Microbalance (QCM).

4. Contact Resistance Method is to measure the electrical resistivity and conductivity with Four Point Contact Resistance Meter.

5. Electrochemical Analysis Method $[12,13]$ is to carry out the test of Linear Sweep Voltammetry (LSV), Polarization Curve (PC), and Electrochemical Impedance Spectroscopy (EIS) and so on to evaluate the corrosion rate and corrosion degree of Ag layer.

6. Microanalysis Method of Corrosion Layer [14-18] is to observe the morphology of the corrosion layer by using Scanning Electron Microscope (SEM), Transmission Electron Microscopy (TEM), and Field Emission Electron Microscope (FE-SEM); to analyze the elements, relative content, valence state, component and chemical structure of the corrosion layer, Auger Electron Spectroscopy (AES), Energy Dispersive X-Ray (EDX), Electron Microprobe Analysis (EMPA), SurfacePlasmon Resonance (SPR), X-ray Photoelectron Spectroscopy (XPS), Secondary lon Mass Spectrometry (SIMS), and Ultraviolet-visible spectrum (UV-Vis) are adopted; to represent the crystal structure of the corrosion layer, X-ray Diffraction (XRD) is used.

7. In Situ Real-Time Monitoring Method [18] includes QCM, Atmospheric Corrosion Monitoring Battery (ACM), Kelvin Scanning Probe (SKP), et al. These in situ monitoring methods are widely used for the analysis and characterization of atmospheric corrosion behavior and mechanism of the metallic materials. 
Based on the analysis of discoloration site and corrosion layer of $\mathrm{Ag}$ objects, the scientists and technicians have developed the corresponding cleaning methods to recover the appearance and performance of corroded Ag, which includes: mechanical cleanings $[19,20]$, chemical cleanings [19-21] (sodium glycinate, thiourea acid solution, thiosulphate solution, formic acid, alcohol, surfactant, acetone, et al.), electrochemical cleanings $[22,23]$ (constant current cathodic reduction, electrolytic pencil), laser cleanings [24-27] [Q-switched Nd: YAG laser, emitting infrared $(1064 \mu \mathrm{m})$, visible $(532 \mathrm{~nm})$ and ultraviolent $(355 \mathrm{~nm}$ ) radiation], Ar ions irradiation cleanings [28], $\mathrm{Ar}$ plasma cleanings $[29,30]$, plasma afterglows cleanings [31], UV/Ozone cleanings [32], and so forth. The characteristics of various cleaning methods are also pointed out. In actual work, we can choose the suitable method as needed.

\section{Corrosion protection method of Ag layer}

How to prevent or slow down the corrosion and discoloration of Ag products has always been one of the hot topics in the field of material protection. Scientists and technicians have done a lot of research on the mechanism and the process of $\mathrm{Ag}$ anti-corrosion and anti-discoloration. There are mainly two ways to be adopted. One is to develop anti-tarnish Ag alloy and the other is to carry out surface treatment of Ag layer.

\subsection{Anti-tarnish Ag alloy}

Developing anti-tarnish Ag alloy makes Ag alloying. There are mainly three types.

1. Alloying of Precious Metals. Pd, Au, Pt or other noble metals is added into Ag matrix to enhance the electrode potential of $\mathrm{Ag}$ and improve its anti-tarnishing property.

2. Alloying of Rare Earth Metals. Trace rare earth elements such as Y, La, Ce and so on is added into Ag matrix to improve its anti-tarnish and sulfuration resistance. In addition, double rare earth elements are added into the Ag matrix. The composite effect of heavy rare earth and light rare earth is more obvious. Like La and Y, they can play the role of Co multiplication or complementarities, which is more beneficial to improve the comprehensive performance of Ag matrix.

3. Alloying of Oxygen Active Elements. A small amount of $\mathrm{Sn}, \mathrm{Si}, \mathrm{Zn}, \mathrm{In}, \mathrm{Ge}$ and other oxygen active elements is added into Ag matrix, which is full of oxygen affinity to form a stable oxide and this oxide is to be used as the protective coating for the Ag matrix. Ag alloying with oxygen active elements is the most popular type in the market presently.

\subsection{Surface treatment of Ag layer}

Ag surface treatment is to utilize chemical or physical methods to form inert protective film on the surface of $\mathrm{Ag}$ products, which makes isolation of Ag from environmental media to avoid the occurrence of $\mathrm{Ag}$ corrosion and discoloration. Surface treatment is a simple and effective method, which mainly includes techniques of surface plating, surface passivation, surface coating, and surface deposition films.

\subsubsection{Surface plating of Ag layer}

Ag surface plating is to employ noble metal plating $(\mathrm{Pd}$, $\mathrm{Au}, \mathrm{Pt}, \mathrm{Rh}, \mathrm{Lr}$, etc.) onto the Ag products, which can effectively prevent the Ag layer from discoloration. But the cost is too high. It is only generally used for a few military products with high reliability and stability and some high-end products.

\subsubsection{Surface passivation of Ag layer}

Ag surface passivation is to deposit a layer of chromate film onto the Ag with chemical or electrochemical methods to passivate the Ag surface and to realize the protective effect. However, $\mathrm{Cr}^{6+}$ can pollute the environment. Therefore, Ag surface passivation technique has been replaced by other techniques in recent years.

\subsubsection{Surface coating of Ag layer}

Ag surface coating is developed with dipping or immersing Ag products into a certain organic anti-coloring solution to build a protective layer onto the Ag against corrosion and discoloration. This technique is the most studied, the most widely used for product types, and the most applied at present.

1. Resin Coating (RC) mainly includes acrylic, organosilicon, epoxy, polyurethane and other resin coatings. The RC film needs a certain thickness to prevent the corrosion and tarnish. Film thickness will weaken the performance of Ag.

2. Plasmapolymer Coating (PC) is discovered and fabricated by the Fraunhofer Institute (IFAM) [33] in Bremen, Germany. There are few application researches up till now.

3. Organic Adsorption Complex Membrane (OACM) involves many different structures of organic matters as anti-corrosion inhibitors adsorbed and complexed 
on the Ag object surface. Guo [34] used 1H-Benzotriazole (BTA) as discoloration inhibitor. Fang et al. [35] applied Benzo tetrazolium (MTA) as anti-corrosion inhibitor. Meanwhile, themselves made AT-2 corrosion inhibitor by himself and good application results have been achieved. Li et al. [36] employed 1- phenyl -5 mercapto tetrazolium (PMTA) in preventing Ag from tarnishing; Zhang et al. [37] built inhibitor PMM, which is a compound of PMTA, 2- mercapto benzoxazole (MBO) and 2-mercapto benzimidazole (MBI). The inhibitors are adsorbed on Ag surface to form a complex membrane. Furthermore, PMM has synergistic effect so that the mixed inhibitors are more effective. Liu et al. [38] used thiadiazole derivatives DMTD, MMTD and DDTD respectively to be chemically adsorbed onto the $\mathrm{Ag}$, which has good corrosion resistance property. Masayoshi [39] adopted Ag substrates with poly (2-vinylpyridine) films as anti-corrosion inhibitor presented exceptionally stable. Chang et al. [40] applied AgNPs with polypyrrole (PPy) shell as anti-corrosion inhibitor provided high protection efficiency. Ali et al. [41] built surfactants deriving from hydroxyphenyl propionic acid and made them be synthesized into HTOPD, HTOPT and HTOPH respectively, which are adsorbed onto the Ag to stabilize the Ag performance. Pan et al. [42] studied thiazolide compounds DPTD, 2-DHPTD, 3-DHPTD, and 4-DHPTD respectively which are adsorbed onto the Ag to inhibit the Ag corrosion.

4. Supramolecular Self-Assembly (SSA) protective film is a molecular layer in ordered arrangement at molecular level. The higher the order and compactness is, the better the effect of anti-corrosion and anti-color is. SSA technique is applied in the Ag corrosion protection and research workers at home and abroad have carried out a series of studies.

Herein, Xu et al. [43] designed graphene oxide (GO)encapsulated AgNP-coated silk fibers with GO serving as the protective film through hyperbranched poly(amideamine) (HBPAA)-directed self-assembly for protecting AgNP coatings to improve its function persistence. Wu et al. [44] invented a method of rapid self-assembly of ultrathin GO film. In this work, a large-area ultrathin and uniform GO film is freely self-assembled at the interface of pentane-water by a rapid process within only $3 \mathrm{~min}$, and subsequently transferred onto the surface of AgNW film by a simple dip coating process, resulting in an impressive improvement in the conductive performance and stability of the AgNWs. Hassan et al. [45] studied the anti-corrosion potentials of chitosan-g-PEG (Ch-g-mPEG) assembled on AgNPs. The results revealed that the inhibition efficiency obtained by $\mathrm{Ch}$-g-mPEG self-assembled on AgNPs is greater. The Ch-g-mPEG was synthesized through Chitosan (Ch) being grafted with poly(ethylene glycol) and the synthesized compound could be classified as mixed-type corrosion inhibitors. Tomas et al. [46] found that significantly better molecular protection for Ag surfaces is afforded by the carboranethiol derivatives, among which 9,12-(HS) ${ }_{2}-1,2-\mathrm{C}_{2} \mathrm{~B}_{10} \mathrm{H}_{10}$ is proved to be particularly effective. Aliaksei et al. [47] investigated the adsorption of isomeric molecules with relatively strong and oppositely oriented molecular dipoles, 1,2-(HS) $-1,2-\mathrm{C}_{2} \mathrm{~B}_{10} \mathrm{H}_{10}$ and 9,12-(HS) ${ }_{2}-1,2-\mathrm{C}_{2} \mathrm{~B}_{10} \mathrm{H}_{10}$, on a flat Ag surface. An effective surface passivation is observed and co-deposition of both derivatives is shown to enable effective and fine adjustment of the surface work function in a desire way. Yang et al. [48] used 2-mercaptobenzothiazole (MBT) to be self-assembled on Ag surface for anticorrosion. The promising inhibition effect of the MBT for Ag from corrosion has been confirmed. Additionally, Yang et al. [49] employed 2-amino-5-mercapto-1,3,4-thiadiazole (AMT) as a protective reagent for $\mathrm{Ag}$ from corrosion. Anti-corrosive effect of the AMT has been ascertained. Megumi et al. [50] investigated the co-adsorption self-assembled films of trithiocyanuric acid (TCA) and 1,3,5-benzenetrithiol (BTT) on evaporated Ag substrate to protect Ag from corrosion. Liang et al. [51], Feng et al. [52] and Du et al. [53] explored the tarnish protection of Ag by octadecanethiol $\left(\mathrm{C}_{18} \mathrm{H}_{37} \mathrm{SH}\right)$ self-assembled protective film onto the Ag surface. Chen et al. [54], Bernard et al. [55], Burleigh et al. [56] and Magali et al. [57] researched the tarnish protection of Ag using a hexadecanethiol $\left(\mathrm{C}_{16} \mathrm{H}_{33} \mathrm{SH}\right)$ self-assembled protective membrane onto the $\mathrm{Ag}$ surface to prevent the tarnishing. Burleigh et al. [58] comparatively studied the self-assembled films of perfluoroalkyl amideethanethiols ( $\left.\mathrm{F}\left(\mathrm{CF}_{2}\right)_{8} \mathrm{CONH}\left(\mathrm{CH}_{2}\right)_{2} \mathrm{SH}\right)$, fluoroalkylthiols $\left(\mathrm{C}_{10} \mathrm{~F}_{21} \mathrm{C}_{2} \mathrm{H}_{4} \mathrm{SH}\right)$, and alkylthiols $\left(\mathrm{C}_{16} \mathrm{H}_{33} \mathrm{SH}\right)$ for the prevention of $\mathrm{Ag}$ tarnish respectively. Liu et al. [59] and Liu et al. [60] constructed self-assembled film of 3-mercaptopropyltrimethoxysilane (MPS) to be adsorbed onto the Ag for protection against corrosion. Liu et al. [61] also explored self-assembled film of Schiff Base to be adsorbed onto the Ag for protection against corrosion.

The above-mentioned explorations and attempts have laid a certain foundation for the development of SSA protective film on Ag objects. How to adjust the film structure, reduce the film defect and enhance the film stability, reproducibility and compactness is the important aspect to improve the protection efficiency of self assembled membrane. These study points should be explored and focused on in the present.

The SSA film belongs to ultrathin organic coating. It is unaffected by the shape of the matrix surface and does not affect the Ag appearance. It only has been for more than ten years for the SSA film to be applied in Ag corrosion, but it has been paid much attention to. It is an 
important research direction for Ag objects anti-corrosion and anti-discoloration.

\subsubsection{Surface deposition of Ag layer}

Ag surface deposition films fabricated through different deposition techniques are able to protect Ag layer from corrosion and discoloration.

1. Magnetron Sputtering (MS) technique is adopted to deposit a protective layer on the $\mathrm{Ag}$ surface against corrosion and discoloration. Xu et al. [62] deposited $\mathrm{SiO}_{2}$ films with MS technique to prevent Ag from corrosion and discoloration.

2. Plasma Beam Sputtering (PBS) technique is utilized to deposit a protective layer on the Ag surface against corrosion and discoloration. Kelsey et al. [63] deposited $\mathrm{NiCrNx}$ films with PBS technique to prevent Ag from corrosion and discoloration.

3. Chemical Vapor Deposition (CVD) technique is employed to deposit a protective layer on the Ag surface against discoloration. Muhammed et al. [64] and Zhao et al. [65] deposited a layer of graphite (Gr) film with CVD to prevent Ag discoloration. Riccardo et al. [66] deposited $\mathrm{SiO}_{2}$ film with Plasma Enhanced Chemical Vapor Deposition (PECVD) to prevent Ag discoloration. Angelini et al. [67] and Saad et al. [68] deposited $\mathrm{SiO}_{x}$ film with PECVD to prevent Ag discoloration.

4. Atomic Layer Deposition (ALD) technique is used to deposit a thin layer of metal oxide (MO) film on the Ag surface against corrosion. The ALD protective film is constructed with the precursors. They are alternately pulsed through reactor, and chemically adsorbed onto the Ag, and which react to form a deposition layer. It is a successive deposition of monatomic layer at atomic level. Besides, it is a transparent nano ultrathin film with high density, high accuracy, no pinhole and high conformality and it does not affect the Ag appearance. Its compactness is better, and its protection performance is higher. The ALD technique applied to the Ag protection has been paid a wide attention to in recent years. A series of studies have been carried out in universities and scientific research institutes at home and abroad.

Herein, Wang et al. [69] demonstrated a laminated $\mathrm{ZnO} /$ $\mathrm{MgO}(\mathrm{ZnMgO})$ as a protective layer on the AgNWs films by using ALD. Ke et al. [70] evaluated the performance of Ag surface treated with cerium oxide $\left(\mathrm{CeO}_{\mathrm{x}}\right)$ by ALD. Yan [71] proposed the ALD of Aluminum doped Zinc Oxide (AZO) for the AgNWs to achieve AgNWs/AZO composite transparent electrodes. Zhang et al. [72] fabricated a stable Ag-carbonate membrane by ALD of $\mathrm{ZrO}_{2}$ overcoat. Paussa et al. [73] protected the Ag surfaces against tarnishing by means of alumina/titania $\left(\mathrm{Al}_{2} \mathrm{O}_{3} / \mathrm{TiO}_{2}\right)$ layer with $\mathrm{ALD}$. Yeh et al. [74] and Ma et al. [75] applied the ALD technique to coat AgNWs and AgNRs respectively with a highly uniform and conformal $\mathrm{TiO}_{2}$ layer to improve their stability. Chen et al. 76], Pham et al. [77] and Duan et al. [78] reported an enhancement of the AgNWs performance by coating with zinc oxide ( $\mathrm{ZnO})$ using the ALD technique. Yang et al. [79], Ma et al. [80], Fedel et al. [81], Ali et al. [82], David et al. [83], Guay et al. [84] and Park et al. [85] evaluated the effectiveness of alumina $\left(\mathrm{Al}_{2} \mathrm{O}_{3}\right)$ fabricated by $A L D$ as a protective coating for $\mathrm{Ag}$ articles against the corrosion.

The ultrathin oxide films deposited and coated on the Ag surface with ALD can improve the anti-corrosion and anti-discoloration of $\mathrm{Ag}$ and its performance can last for a long time. Research shows that the nano transparent ultrathin oxide films fabricated with ALD have a good application prospect. The ALD protective films applied in the $\mathrm{Ag}$ anti-corrosion and anti-discoloration lays the foundation to develop an effective corrosion protection method for Ag layer.

\section{Research prospect}

Owing to the development of industrialization, pollutant content in atmospheric environment keeps increasing and the problem of discoloration of Ag under natural conditions is becoming more and more serious. Also, in practical work and application, the corrosion protection and anti-discoloration of $\mathrm{Ag}$ are weaker. They are all the inconveniences for the efficacy of the functional Ag layer. Therefore, it is urgent to find an effective corrosion protection method for Ag layer.

A variety of protection methods for Ag corrosion have been proposed by the scientific community, none of which perfectly satisfies the requirements of all applications. So far, there has been no widely recognized method, and only certain effects have been achieved and limited commercial applications have been obtained. The Ag alloying can effectively alleviate the discoloration of Ag, but the alloy component has strict requirements and its application area is also limited. For pure Ag products, they are mainly through surface treatment. It is to produce a protective film on the $\mathrm{Ag}$ surface, which would isolate Ag from environmental media to avoid the Ag discoloration. For the surface treatment of $\mathrm{Ag}$, the following requirements should be taken into consideration: (1) It should keep the original appearance of Ag. (2) The surface treatment should be nontoxic, harmless, stable and easy of processing. (3) It should have great maneuverability. (4) The thickness should be as thin as possible. (5) The film should be easily renovated and removed. (6) The film 
should have durability and ability of withstanding wear. (7) The treatment process should have low cost.

As a result of scientific research and practical application, the SSA and ALD technologies are very potential to be applied in the development of protective film for Ag layer. For SSA, it is to design the supra-molecular structure and the component of self-assembly system, to construct the interface recognition of molecules on the Ag surface, to complete the orderly arrangement at molecular level, and to form the self assembled membrane on the Ag surface to realize the protection of Ag. For ALD, it is to select the precursors and the carriers of reactant, which have capability of saturated chemical adsorption and reaction with $\mathrm{Ag}$, and to form the nano ultrathin films at atomic level to realize the protection of Ag. For the SSA and ALD techniques to be applied in the Ag protection, a systematic and in-depth study needs to be carried out.

Ag discoloration is a complicated phenomenon. Therefore, the Ag anti-discoloration protection needs comprehensive treatment. In every link, such as production, assembly, storage, transportation, display and use, it should be carried out comprehensive control from all aspects. In production, it is to purify air quality and to control temperature and humidity in the production workshop. During assembly, operators should wear clean gloves to prevent hand sweat, grease and other corrosive substances from sticking to the Ag surface. During transportation, it should be packed with gas phase antirust membrane, or anti-color paper and anti-discoloration fabric, through isolation and chemical action to retard the Ag discoloration. During storage and display, it should be put in a sealed cabinet, in which some substances can eliminate pollutants around Ag through reacting with sulfur, oxygen, chlorine, etc., so the Ag discoloration has been slowing down.

The Ag corrosion and discoloration is a persistent problem that puzzles its application. The Ag corrosion protection has always been a research difficulty. We need to continue to work unremittingly for research and development of appropriate methods, which are suitable for the needs and requirements in practice.

Acknowledgements The authors are thankful to the National Natural Science Foundation of China (51103083) for funds.

\section{Compliance with ethical standards}

Conflict of interest The authors declare that they have no conflict interest.

\section{References}

1. Yang CJ, Liang $\mathrm{CH}$, Wang $P$ et al (2007) Investigation of the tarnish film on the surface of commemoration silver coin. Rare Metal Mater Eng 36(4):629-632

2. Yang CJ, Liang CH, Liu X (2007) Tarnishing of silver in environments with sulphur contamination. Anti-Corros Methods Mater 54(1):21-26

3. Kim H, Payer JH (2006) The tarnish process of silver in $\mathrm{H}_{2} \mathrm{~S}$ environments. Corros Sci Technol 5(6):206-212

4. Yan LD, Xiao K, Yi P et al (2017) The corrosion behavior of PCB$\mathrm{ImAg}$ in industry polluted marine atmosphere environment. Mater Des 115:404-414

5. Wiesinger R, Martina I, Kleber C et al (2013) Influence of relative humidity and ozone on atmospheric silver corrosion. Corros Sci 77:69-76

6. Jiu JT, Wang J, Sugahara T et al (2015) The effect of light and humidity on the stability of silver nanowire transparent electrodes. RSC Adv 5:27657-27664

7. Vargas OL, Valdez SB, Veleva ML et al (2009) The corrosion of silver in indoor conditions of an assembly process in the microelectronics industry. Anti-Corros Methods Mater 56(4):218-225

8. Mcmahon MD, Lopez R, Meyer HM et al (2005) Rapid tarnishing of silver nanoparticles in ambient laboratory air. Appl Phys B Lasers Opt 80:915-921

9. Wang XL, Santschi C, Martin OJF (2017) Strong improvement of long-term chemical and thermal stability of plasmonic silver nanoantennas and films. Adv Sci News 13:1700044

10. Lee KS, El-Sayed MA (2006) Gold and silver nanoparticles in sensing and imaging: sensitivity of plasm on response to size, shape, and metal composition. Phys Chem 110:19220-19225

11. Oates TWH, Losurdo M, Noda S et al (2013) The effect of atmospheric tarnishing on the optical and structural properties of silver nanoparticles. J Phys D Appl Phys 46:145308

12. Amor YB, Sutter E, Takenouti $\mathrm{H}$ et al (2014) Electrochemical study of the tarnish layer of silver deposited on glass. Electrochim Acta 131:89-95

13. Capelo S, Homem PM, Cavalheiro J et al (2013) Linear sweep voltammetry: a cheap and powerful technique for the identification of the silver tarnish layer constituents. J Solid State Electrochem 17:223-234

14. Janette OC, Jose LRS, Edgar CG et al (2017) Surface analysis of the tarnishing layer in silver alloys. MRS Adv 2(63):3983-3989

15. Navina M, Abhai M (2000) Study of tarnished films formed on silver by exposure to $\mathrm{H}_{2} \mathrm{~S}$ with the surface-plasmon resonance technique. Appl Opt 39(28):5214-5220

16. Mezzi A, Riccucci C, Caro TD et al (2014) Combined use of SAXPS, XRD and SEM + EDS for the micro-chemical characterisation of Ag-based archaeological artefacts. Surf Interface Anal 46:801-806

17. Dowsett MG, Adriaens A, Soares M et al (2005) The use of ultralow-energy dynamic SIMS in the study of the tarnishing of silver. Nucl Instrum Methods Phys Res B 239:51-64

18. Zhu YL (2017) The research on corrosion behavior of silver relics materials in the simulate museum lighting environment. East China University of Science and Technology, Master Dissertation

19. Teresa P, Blanca RB, Emma G et al (2016) A comparative study of cleaning methods for tarnished silver. J Cult Herit 17:20-26

20. Teresa P, Blanca RB, Emilio C (2018) Evaluation of cleaning treatments for tarnished silver: the conservation's perspective. Int J Conserv Sci 9(1):81-90

21. Joao CDFJ, Samara SA, Joao HRB (2014) Removal of brownishblack tarnish on silver-copper alloy objects with sodium glycinate. Appl Surf Sci 317:67-72 
22. Novakovic J, Vassiliou P, Georgiza E (2013) Electrochemical cleaning of artificially tarnished silver. Int J Electrochem Sci 8:7223-7232

23. Christian D, Romain J, Denise W et al (2016) A new electrolytic pencil for the local cleaning of silver tarnish. Stud Conserv 61(3):162-173

24. Palomar T, Oujja M, Llorente I et al (2016) Evaluation of laser cleaning for the restoration of tarnished silver artifacts. Appl Surf Sci 387:118-127

25. Omar AK, Awad AZ, Amal K et al (2016) Evaluation laser cleaning of corroded archaeological silver coins. MAA 16(1):135-143

26. Christian D, Eric T, Rene LG et al (2003) Laser cleaning of tarnished silver and copper threads in museum textiles. J Cult Herit 4(1):152S-156S

27. Bojana R, Slavica R, Suzana P et al (2017) Preliminary investigation on the use of the Q-switched Nd:YAG laser to clean corrosion products on museum embroidered textiles with metallic yarns. J Cult Herit 23:128-137

28. Takahiro K, Ozaki K, Wada M et al (2013) Irradiation-induced brightening of tarnished Ag nanoparticles. Nucl Instrum Methods Phys Res B 315:218-221

29. Ozaki K, Nishiyama F, Takahiro K (2015) Plasma-induced brightening and coarsening of tarnished Ag nanoparticles. Appl Surf Sci 357:1816-1822

30. Hosomi K, Ozaki K, Nishiyama F et al (2018) Enhancement in volatile organic compound sensitivity of aged Ag nanoparticle aggregates by plasma exposure. Appl Surf Sci 427:848-853

31. Olivier S, Patrick S, Arianna G et al (2018) How effective are reducing plasma afterflows at atmospheric pressure in removing sulphide layers: application on tarnished silver, sterling silver and copper. Surf Interface Anal 50:32-42

32. Hacke AM, Carr CM, Brown A et al (2003) Investigatijon into the nature of metal threads in a renaissance tapestry and the cleaning of tarnished silver by UV/Ozone (UVO) treatment. J Mater Sci 38(15):3307-3314

33. Frey T, Kogel M (2003) Tarnish protection of silver jewels by plasmapolymer coatings. Surf Coat Technol 173-174:902-904

34. Guo Y (2008) Study on the preparation of cotton antibacterial fabrics with Ag carring inorganic composite antibacterial agent. Northwest University, Master Dissertation

35. Fang JL, Fang X (2007) Review of metal surface complex protective film (II) - anti discoloration complex film of silver. Mater Prot 40(10):85-89

36. Li HY, Yang ZD, Yan YQ et al (2005) Study on $\mathrm{H}_{2} \mathrm{~S}$ corrosion resistance performance of PMTA for silver coating. J Mater Metall 4(1):74-80

37. Zhang DS, Cai LK, Zhu HF et al (2002) Study of anti-tarnishing synergistic effect of inhibitors for silver. Mater Prot 35(2):26-27

38. Liu L, Pan XN, Xing JJ et al (2015) Anti-corrosion behavior of thiadiazole derivatives for silver strip in hydrogen sulfide solutions. Anti-Corros Methods Mater 62(6):353-362

39. Masayoshi K (2016) Long-term stabilization of mixed silver nanoparticles on an Al surface with poly(2-vinylpyridine) films. Vib Spectrosc 86:61066

40. Chang M, Kim T, Park HW et al (2012) Imparting chemical stability in nanoparticulate silver via a conjugated polymer casing approach. Appl Mater Interfaces 4:4357-4365

41. Ali AAE, Elbasiony NM, Samy MS et al (2018) Studying the corrosion inhibition of some prepared nonionic surfactants based on 3-(4-hydroxyphenyl) propanoic acid and estimating the influence of silver nanoparticles on the surface parameters. J Mol Liq 249:304-317

42. Pan XN, Liu L, Zhang Q et al (2016) Corrosion inhibition and performance evaluation on 2,5-diaryl-1,3,4-thiadiazole and its derivatives. Surf Interface Anal 48:373-382
43. Xu SJ, Song JC, Zhu CH et al (2017) Graphene oxide-encapsulated Ag nanoparticle-coated silk fibers with hierarchical coaxial cable structure fabricated by the molecule-directed self-assembly. Mater Lett 188:215-219

44. Wu CH, Jiu JT, Araki T et al (2016) Rapid self-assembly of ultrathin graphene oxide film and application to silver nanowire flexible transparent electrodes. RSC Adv. 6:15838-15845

45. Hassan HHH, Eid MA, Emad AB et al (2016) Synthesis, characterization and anticorrosion potentials of chitosan-g-PEG assembled on silver nanoparticles. Int J Biol Macromol 83:297-305

46. Tomas B, Zdenek B, Vladimir H et al (2010) Carborane-thiol-silver interactions. A comparative study of the molecular protection of silver surfaces. Surf Coat Technol 204:2639-2646

47. Aliaksei V, Laetitia B, Olga G et al (2016) Adsorption of oriented carborane dipoles on a silver surface. Phys Status Solidi B 253(3):591-600

48. Yang HF, Sun YP, Ji JH et al (2008) 2-mercaptobenzothiazole monolayers on zinc and silver surfaces for anticorrosion. Corros Sci 50(11):3160-3167

49. Yang HF, Sun XJ, Zhu J et al (2007) Surface enhanced raman scattering, in situ spectro-electrochemical, and electrochemical impedance spectroscopic investigations of 2-Amino-5-mercapto-1,3,4-thiadiazole monolayers at a silver electrode. J Phys Chem C 111(22):7986-7991

50. Megumi I, Toshihiko H, Naoki O (2011) Coadsorption self-assembled monolayers of trithiocyanuric acid and 1,3,5-benzenetrithiol on an evaporated silver film. J Mole Struct 1002(1-3):179-186

51. Liang CH, Yang CJ, Huang NB (2009) Tarnish protection of silver by octadecanethiol self-assembled monolayers prepared in aqueous micellar solution. Surf Coat Technol 203:1034-1044

52. Feng YL, Zhang HR, Zhao QR et al (2016) Study on corrosion protection properties of self-assembly membrane on electroless silver plating layer. Synth Fiber in China 45(10):30-34

53. Du W, Wan L, Li JJ et al (2013) Anticorrosion action and adsorption mechanism of the self-assemble monolayers on silver in aqueous solution. Rare Metal Mater Eng 42(3):545-549

54. Chen BR, Lu WY, Chen DY et al (2017) Tarnish protection for silver using self-assembled monolayers of alkanethiols with different chain lengths. Corros Prot 38(6):429-433

55. Bernard MC, Dauvergne E, Evesque $M$ et al (2005) Reduction of silver tarnishing and protection against subsequent corrosion. Corros Sci 47:663-679

56. Burleigh TD, Gu Y, Donahey G et al (2001) Tarnish protection of silver using a hexadecanethiol self-assembled monolayer and descriptions of accelerated tarnish tests. Corrosion 57(12):1066-1074

57. Magali E, Michel K, Hisasi T (2004) The formation of self-assembling membrane of hexadecane-thiol on silver to prevent the tarnishing. Electrochim Acta 49:2937-2943

58. Burleigh TD, Shi C, Kilic S et al (2002) Self-assembled monolayers of perfluoroalkyl amideethanethiols, fluoroalkylthiols, and alkylthiols for the prevention of silver tarnish. Corrosion 58(1):49-56

59. Liu L, Chu MY, Xing JJ et al (2011) Self-assembled monolayer film morphology and corrosion inhibition. Sci Technol Eng 11(13):3059-3062

60. Liu JH, Wang YH, Guo ZR et al (2004) Self-assembled layer on silver for protection against corrosion. J Chem Ind Eng (China) 55(10):1674-1677

61. Liu L, Chu MY, Xing JJ et al (2011) Synthesis of Schiff base and analysis for protection performance of SAMs on silver surface. $J$ Petrochem Univ 24(1):37-40

62. Xu YJ, Cai QW, Yang XX et al (2012) Preparation of novel $\mathrm{SiO}_{2}$ protected $\mathrm{Ag}$ thin films with high reflectivity by magnetron sputtering for solar front reflectors. Sol Energy Mater Sol Cells 107:316-321 
63. Kelsey AF, Chung TC, Zachary RL et al (2017) Environmental durability of protected silver mirrors prepared by plasma beam sputtering. Appl Opt 56(4):C75-C86

64. Muhammed EA, Golap K, Subash S et al (2013) Chemical vapor deposition of graphene on silver foil as a tarnish-resistance coating. Phys Status Solidi (Rapid Res Lett 7) 12:1076-1079

65. Zhao YD, Xie YZ, Yeung YH et al (2013) Highly impermeable and transparent graphene as an ultra-thin protection barrier for $\mathrm{Ag}$ thin films. J Mater Chem C 1:4956-4961

66. Riccardo A, Francesco F, Fabio P et al (2005) Protection of slverbased alloys from tarnishing by means of plasma-enhanced chemical vapor deposition. Plasma Process Polym 2:91-96

67. Angelini E, Grassini S, Parvis M (2010) Silver artefacts: plasma deposition of SiOx protective layers and tarnishing evolution assessment. Corros Eng, Sci Technol 45(5):334-340

68. Saad AT, Luca V, Luca A et al (2014) Deposition of SiOx layer by plasma-enhanced chemical vapor deposition for the protection of silver (Ag) surfaces. Radiat Eff Defects Solids 169(3):217-224

69. Wang L, Huang DC, Li M et al (2017) Highly transparent and thermal-stable silver nanowire conductive film covered with $\mathrm{ZnMgO}$ by atomic-layer-deposition. J Phys Chem Solids 111:328-334

70. Ke CN, Gwon DH, Kim MJ et al (2016) Nanoporous silver cathode surface treated by atomic layer deposition of $\mathrm{CeO}_{x}$ for lowtemperature solid oxide fuel cells. Nanotechnology 27:185403

71. Yan XZ (2016) Studies on the fabrication and optoelectric properties of transparent conductive films based on silver nanowires and metal oxide composites. Northeast Normal University, Doctoral Dissertation

72. Zhang $\mathrm{P}$, Tong JJ, Jee $\mathrm{Y}$ et al (2016) Stabilizing a high-temperature electrochemical silver-carbonate $\mathrm{CO}_{2}$ capture membrane by atomic layer deposition of a $\mathrm{ZrO}_{2}$ overcoat. Chem Commun 52:9817-9820

73. Paussa L, Guzman L, Marin E et al (2011) Protection of silver surfaces against tarnishing by means of alumina/titania-nanolayers. Surf Coat Technol 206:976-980

74. Yeh $\mathrm{MH}, \mathrm{Chen} \mathrm{PH}$, Yang YC et al (2017) Investigation of $\mathrm{Ag}-\mathrm{TiO}_{2}$ interfacial reaction of highly stable Ag nanowire transparent conductive film with conformal $\mathrm{TiO}_{2}$ coating by atomic layer deposition. Appl Mater Interfaces 9:10788-10797

75. Ma LW, Huang Y, Hou MJ et al (2015) Ag nanorods coated with ultrathin $\mathrm{TiO}_{2}$ shells as stable and recyclable SERS substrates. Sci Rep 5:15442
76. Chen D, Liang JJ, Liu C et al (2015) Thermally stable silver nanowire-polyimide transparent electrode based on atomic layer deposition of zinc oxide on silver nanowires. Adv Funct Mater 25:7512-7520

77. Pham AT, Nguyen XQ, Tran DH et al (2016) Enhancement of the electrical properties of silver nanowire transparent conductive electrodes by atomic layer deposition coating with zinc oxide. Nanotechnology 27:335202

78. Duan YH, Duan Y, Chen P et al (2015) High-performance flexible Ag nanowire electrode with low-temperature atomic-layer-deposition fabrication of conductive-bridging $\mathrm{ZnO}$ film. Nanoscale Res Lett 10:1-6

79. Yang YL, Bai XS, Li N et al (2017) Anti-corrosion properties of $\mathrm{Al}_{2} \mathrm{O}_{3}$ depositing on the surface of silver jewelry. Sci Technol Eng 17(28):172-175

80. Ma LW, Huang Y, Hou MJ et al (2015) Silver nanorods wrapped with ultrathin $\mathrm{Al}_{2} \mathrm{O}_{3}$ layers exhibiting excellent SERS sensitivity and outstanding SERS stability. Sci Rep 5:12890

81. Fedel M, Zanella C, Rossi S et al (2014) Corrosion protection of silver coated reflectors by atomic layer deposited $\mathrm{Al}_{2} \mathrm{O}_{3}$. Sol Energy 101:167-175

82. Ali K, Duraisamy N, Kim CY et al (2014) $\mathrm{Al}_{2} \mathrm{O}_{3}$ coatings fabrication on silver nanowires through low temperature atomic layer deposition. Mater Manuf Process 29(9):1056-1061

83. David MF, Juan JL, Andrew CP et al (2017) Effect of intermediate layers on atomic layer deposition-aluminum oxide protected silver mirrors. J Astron Telesc Inst 3(3):034001

84. Guay JM, Killaire G, Gordon PG et al (2018) Passivation of plasmonic colors on bulk silver by atomic layer deposition of aluminum oxide. Langmuir 34:4998-5010

85. Park SW, Han GD, Choi HJ et al (2018) Evaluation of atomic layer deposited alumina as a protective layer for domestic silver articles: anti-corrosion test in artificial sweat. Appl Surf Sci 441:718-723

Publisher's Note Springer Nature remains neutral with regard to jurisdictional claims in published maps and institutional affiliations. 